EXTENDED REPORT

\title{
Visual function and car driving: longitudinal results 5 years after cataract surgery in a population
}

\author{
E Mönestam, B Lundquist, L Wachtmeister
}

Br J Ophthalmol 2005;89:459-463. doi: 10.1136/bjo.2004.051151

See end of article for authors' affiliations

.....................

Correspondence to: E Mönestam, Department of Clinical Science/ Ophthalmology, Umeå

University, S-901 85

Umeå, Sweden;

eva.monestam@vll.se

Accepted for publication 1 September 2004

\begin{abstract}
Aims: To determine visual function in drivers who had cataract surgery 5 years previously, and to analyse longitudinal data, by comparing preoperative and postoperative changes in subjective driving ability and objective visual function.

Methods: All patients (810) who underwent cataract surgery, during a 1 year period, were prospectively studied. Data regarding present driving status were collected from self administered questionnaires and visual acuity (VA) data were measured before and after surgery. All patients who were alive 5 years later were invited to participate with a new eye examination and questionnaire.

Results: Before surgery 36 active drivers $(16 \%)$ did not fulfil the visual requirements for driving; with improved glasses this number could be reduced to $24(11 \%) .5$ years after surgery, the corresponding figures were $5 \%$ and $3 \%(5 / 174)$, respectively. Before surgery $50 \%$ stated visual difficulties while driving in daylight and $79 \%$ in darkness. A few months and 5 years after surgery the corresponding figures were $6 \%$ and $5 \%$, respectively, for daytime driving and $34 \%$ and $44 \%$, respectively, for night-time driving.

Conclusions: Long term results regarding cataract surgery in car drivers are beneficial. 5 years after surgery only a few patients drove not fulfilling the requirements, but there were a larger proportion of patients with problems driving in darkness compared with a few months after surgery.
\end{abstract}

$\mathrm{P}$ revious research has found the occurrence of cataract was significantly associated with difficulties in driving. Cataract patients were more likely to report difficulties in challenging driving situations, and more often experienced a restriction in their driving ability, and a decrease in their safety on the road. Drivers with cataract were 2.5 times more likely to have a history of at-fault crash involvement in the previous 5 years adjusted for miles driven/week and days driven/week.

In an earlier publication we reported that subjective and objective visual function in drivers was substantially improved after cataract surgery. ${ }^{2}$ Moreover, it was not uncommon for drivers with cataract to drive with vision not fulfilling the visual requirements before surgery. To the authors' knowledge, no long time results of cataract surgery outcome in drivers have yet been published.

\section{MATERIALS AND METHODS}

\section{Study population}

All patients who underwent cataract surgery, between 1 June 1997 and 31 May 1998, at Norrlands University Hospital in Umeå, Sweden, were prospectively registered. All cataract surgery of the population was performed at the university clinic, as there are no other public or private operating eye clinics in the area. The admitting area has a population of about 180000 people and is sparsely populated with only 3.8 inhabitants per square kilometre. The means of public transportation are few and the population must to a large extent rely on car driving.

\section{Inclusion and exclusion criteria in 1997-8, and response rate}

In all, 928 cases of cataract surgery were registered during the 1 year period. Patients who underwent cataract surgery for other reasons than restoring vision, or had cataract surgery combined with other types of ocular surgery, were excluded. Also excluded were patients with dementia making them unable to cooperate with a questionnaire. The study included a total of 810 senile and presenile cataract patients.

The response rate for all patients including dead patients was $94 \%$. No significant differences in sex were found between the dropouts and those included, but the dropouts were significantly older than the study patients (mean age 78.7 years versus $74.6, \mathrm{p}<0.0001$ ). The frequency of cataract surgery for the time period studied was 5.2 per 1000 population.

\section{Preoperative and postoperative data}

The following data were recorded; age, sex, first or second eye surgery, presenting and best corrected monocular visual acuity (VA) of both eyes before and after surgery (Monoyer Granström letter chart), type of surgery and complications, and ocular co-morbidity.

Age related macular degeneration (AMD) was defined as pigment changes or drusen in the macular area only in conjunction with a VA of 20/30 or worse after surgery. ${ }^{3}$

\section{Data collected 5 years after surgery}

Five years after surgery, we checked with the Swedish Population Register which patients were still alive; 220 patients were dead $(220 / 810 ; 27 \%)$. All survivors were asked to participate with the same questionnaire, and a new eye examination. Forty seven patients could not participate because of dementia, seven could not be located, and six refused. Five hundred and thirty patients participated with the questionnaire-that is, $99 \%$ of the eligible sample (530/ $536)$, and $90 \%$ of survivors (530/590). In addition to the questionnaire 467 patients also underwent an eye examination, making up $79 \%$ of survivors (467/590). The major reason for not participating with the eye examination was trouble/unwillingness to travel to the eye clinic, either because of illness or long distance.

Abbreviations: $A M D$, age related macular degeneration; BCVA, best corrected visual acuity; VA, visual acuity 


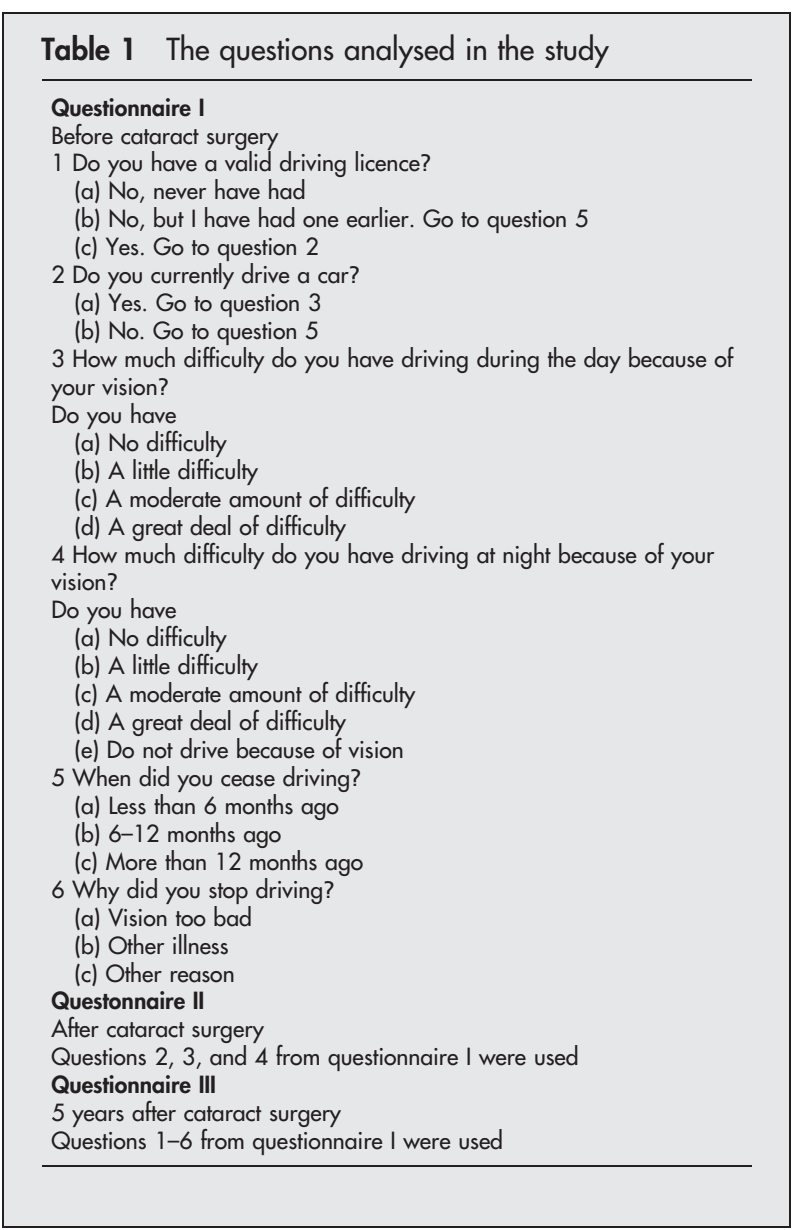

The eye examination was performed in the same manner as in 1997-8, with the exception that an EDTRS VA chart was used. Patients with failure to read any letters were tested using counting fingers (CF), hand movements (HM), and light perception (LP), and scored as outlined in earlier publications. ${ }^{45}$

\section{Questionnaires}

One to 2 weeks before surgery a self administered questionnaire was mailed to the patients. On the day of surgery, the questionnaire was delivered by the patient to the clinic. We checked that the questions had been understood and completely answered. Approximately 1 month after the patients had received their prescription spectacles (if required) a second questionnaire was mailed to them. Five years after surgery a similar questionnaire was mailed to all surviving patients who were able to participate. Those who had an eye examination delivered the questionnaire to the clinic, and those who did not participate with an examination mailed the questionnaire to the research team.

The questionnaires contained the questions used by Steinberg et $a l^{5}$ in their questionnaire (VF-14), and a few additional questions used in our previous study. ${ }^{2}$ The VF-14 is extensively validated and has been found to have high reliability, responsiveness, and validity. ${ }^{5-7}$ The questions analysed in the present study are presented in table 1 .

\section{Requirements for driving}

As Sweden is a member of the European Union (EU), the minimal legal requirements for non-commercial car driving (fitness to drive) is a binocular best corrected VA (BCVA) of $20 / 40$ or better. Drivers with only one functional eye must have a minimum acuity of $20 / 33 .^{8}$

\section{Statistical methods}

Two sample $t$ tests were used to compare differences in age between patients with and without a driving licence. Yates's corrected $\chi^{2}$ test or Fisher's exact tests were used to analyse the $2 \times 2$ frequency tables. All tests were two sided and $p$ values $<0.05$ were considered statistically significant. Analyses were performed by means of the SPSS software 11.5 .

\section{RESULTS}

Demographic and VA data, in relation to holding a driving licence

Figure 1 shows a flow chart of the driving status before and after surgery, and 5 years later of the patients operated during the 1 year period (1997-98).

Before surgery 407 (50\%) patients had a valid driving licence, $50(6 \%)$ had had a licence earlier in life, and 353 $(46 \%)$ had never had a licence.

The mean age of those with driving licences was significantly lower (70.7 years (SD 11)) than those without licences ( 78.7 years (SD 8.8); $\mathrm{p}<0.0001$ ), table 2 . Fifty six per cent of those with driving licences were men (226/407), 86\% $(346 / 403)$ of those without licences were women (table 2 ).

Patients without driving licences had significantly worse VA of the eye to be operated and the better eye, both before and after surgery. Before surgery, $32 \%$ of the patients with driving licences did not fulfil the visual requirements for driving before surgery. A new refraction and a change to optimal glasses would only reduce this figure to $25 \%$. After surgery, only $5 \%$ of those with driving licences did not fulfil the visual requirements.

\section{Relation between driving status and fulfilment of VA requirements for driving}

Before surgery, 55\% (224/407) of the patients with a driving licence were active drivers, $66 \%$ of these were men (fig 1 ).

Before surgery 36 active drivers $(16 \% ; 36 / 224)$ did not fulfil the visual requirements for driving. With improved glasses this number could be reduced to 24 (11\%) (table 3). Figure 2 shows the distribution of VA of the better eye of these drivers.

Those who drove without fulfilling the legal requirements before surgery were significantly older ( 74.4 years versus 67.2 years, $\mathrm{p}<0.00001$ ).

After surgery 285 patients were drivers (fig 1). There were only two patients $(2 / 285 ; 1 \%$, ) who drove without fulfilling the visual requirements for driving. Both of them had a VA just below the limit. Both of these two patients did not drive 5 years later.

Five years after surgery 189 patients were active drivers, $63 \%$ of the eligible patients with driving licence (fig 1). VA data were available from 174 drivers, as 15 did only participate with the questionnaire. Nine patients $(5 \%)$ did not fulfil the legal VA requirements with the worst VA of $20 / 83$. With improved spectacles five patients (3\%) remained below the limit, most of them by only a few letters.

Those who did not fulfil the legal requirements were significantly older $(69.6 v 78.2$ years; $\mathrm{p}<0.0001)$. There were also an increased percentage of males $(7 \% \vee 3 \%$; $=0.32)$, and patients with only the first eye operated $(57 \% \vee 30 \%$; $\mathrm{p}=0.13$ ), but these differences were not statistically significant.

Six patients of the nine (67\%) who did not fulfil the legal requirements had a diagnosis of ARM before surgery, versus $11 \%$ of those who had sufficient VA $(\mathrm{p}<0.0005)$. Five years after surgery eight of nine patients (89\%) with too low VA had ARM, and the remaining patient had glaucoma as major diagnosis for reduced VA. 


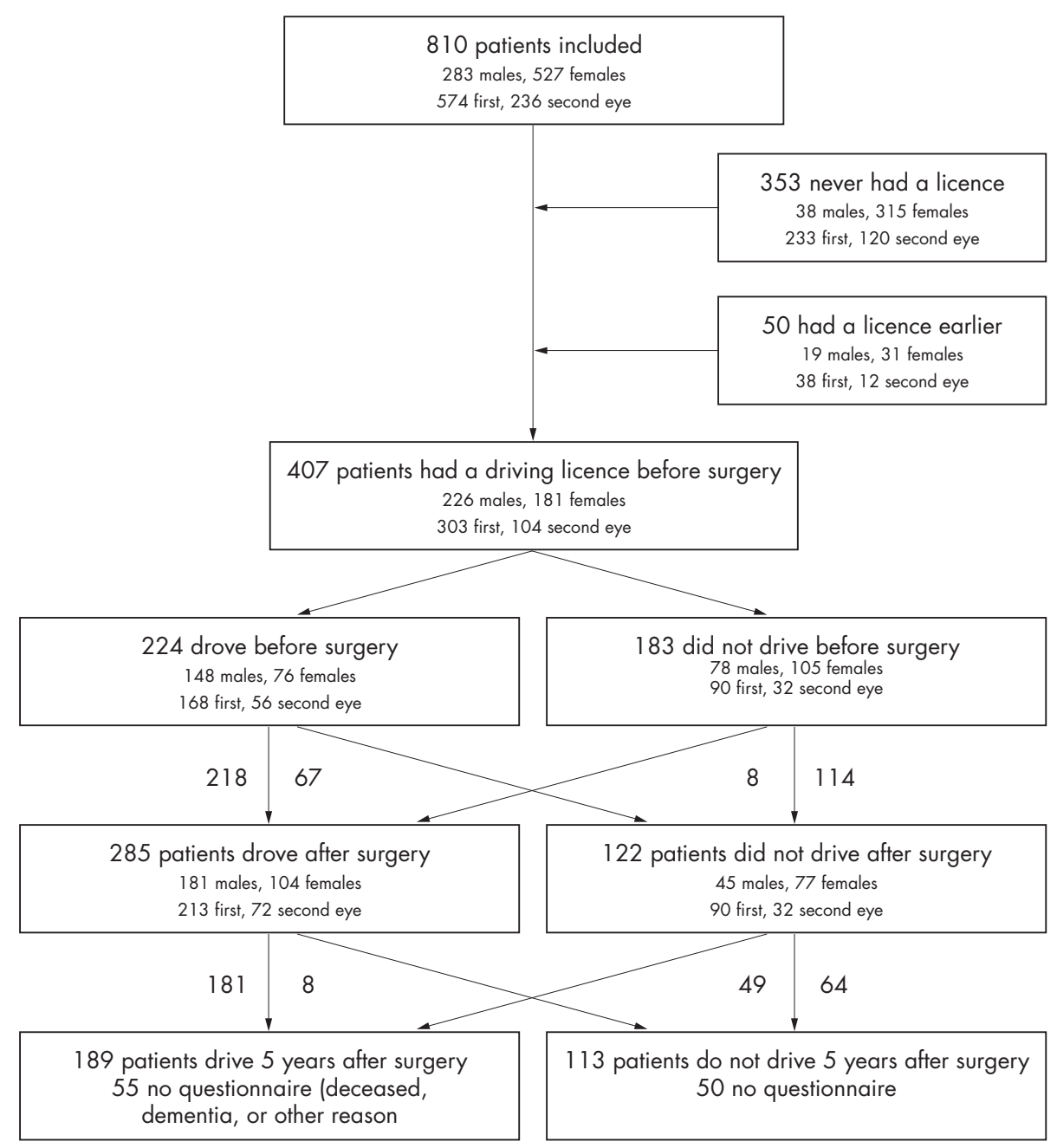

\section{Change in driving status after surgery, and 5 years later}

Sixty seven patients $(67 / 183 ; 37 \%)$ who did not drive before surgery started to drive after surgery. Before surgery, $46 \%$ $(31 / 67)$ and $35 \%(24 / 67)$ of these did not fulfil the visual requirements for driving regarding presenting and best corrected VA of the better eye, respectively. After surgery all of these active drivers had sufficient VA to drive legally. Five
Figure 1 Flow chart of the driving status before and after surgery, and 5 years later.

Table 2 Demographic variables and VA data for all patients operated in 1997-8

\begin{tabular}{|c|c|c|c|}
\hline & $\begin{array}{l}\text { Driving } \\
\text { licence }\end{array}$ & $\begin{array}{l}\text { No driving } \\
\text { licence }\end{array}$ & p Value \\
\hline No of patients & 407 & 403 & \\
\hline Mean age (years) (SD) & $70.8(11.0)$ & $78.7(8.8)$ & $<0.0001^{\star}$ \\
\hline Age range (years) & $36-91$ & $30-96$ & \\
\hline Males (\%) & 56 & 14 & $<0.0001^{\text {** }}$ \\
\hline First eye surgery (\%) & 74 & 67 & $0.024^{* *}$ \\
\hline $\begin{array}{l}\text { Presenting visual acuity } 20 / 200 \text { or less of the eye } \\
\text { to be operated (\%) }\end{array}$ & 48 & 60 & 0.0009 ** \\
\hline $\begin{array}{l}\text { Best corrected VA } 20 / 200 \text { or less of the eye to be } \\
\text { operated (\%) }\end{array}$ & 44 & 56 & $0.0016^{* *}$ \\
\hline $\begin{array}{l}\text { Presenting visual acuity less than } 20 / 40 \text { of the } \\
\text { better eye before surgery (\%) }\end{array}$ & 32 & 52 & $<0.0000^{* *}$ \\
\hline $\begin{array}{l}\text { Best corrected VA less than } 20 / 40 \text { of the better eye } \\
\text { before surgery (\%) }\end{array}$ & 25 & 48 & $<0.0000^{* *}$ \\
\hline $\begin{array}{l}\text { Best corrected VA } 20 / 40 \text { or less of the operated } \\
\text { eye after surgery (\%) }\end{array}$ & 10 & 23 & $<0.0000^{* *}$ \\
\hline $\begin{array}{l}\text { Best corrected VA } 20 / 40 \text { or less of the better eye } \\
\text { after surgery (\%) }\end{array}$ & 5 & 18 & $<0.0000^{* *}$ \\
\hline
\end{tabular}




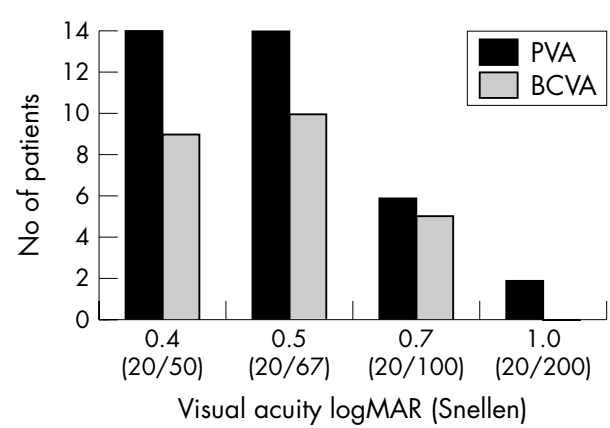

Figure 2 Distribution of presenting (PVA) and best corrected visual acuities (BCVA) of the better eyes, in patients driving but not fulfilling the visual requirements, before cataract surgery.

and the 19 surviving patients from the group of 50 who were ex-drivers already before surgery (fig 1 ). Table 4 shows the reasons stated for not driving. Most of those who thought their vision was too bad $(65 \%)$ did not fulfil the visual requirements. Surprisingly few did not drive because of health problems other than ocular co-morbidity (26/132; $20 \%)$.

\section{Subjective visual problems while driving before and after surgery, and after 5 years}

Before surgery $50 \%$ (110/222) of the patients reported visual difficulties with daytime driving (table 3 ). After surgery this figure had decreased to $6 \%(17 / 281)$. Regarding driving in darkness, 69\% (150/217) reported visual difficulties before surgery, $21 \%(46 / 217)$ had no visual problems, and $10 \%$ (21/217) never drove in darkness. After surgery, 24\% patients had visual difficulties when driving in darkness $(67 / 281)$, and $28(10 \%)$ never drove in darkness.

Five years after cataract surgery 95\% (179/188) of the patients reported no visual difficulties during daytime driving. The corresponding figure for night driving was 56\% $(105 / 188)$.Twenty two patients $(12 \%)$ had visual difficulties to such a large degree they never drove during the night (table 3 ). There was a statistically significant larger percentage of patients with visual difficulties while driving at night $(p<0.05) 5$ years after surgery compared with a few months after surgery.

\section{DISCUSSION}

Onset of cataract and its surgery have both legal and practical consequences for driving. The data presented might be compared with a similar study by us from 1992. ${ }^{2}$ The frequency of cataract surgery in 1997-8 was considerably higher than in 1992 (5.2 $v 3.3$ per 1000 population, respectively).

We found that $11 \%$ of the patients who drove before surgery had a BCVA of less than 20/40, and the corresponding figure from 1992 was 23\%. Increased frequency of surgery reduces the proportion of patients who drive preoperatively with a VA below the requirements. This finding coincides with previous research that increasing frequency of cataract surgery will result in better VA of both eyes before surgery. ${ }^{9}{ }^{10}$

We found that half of those who were active drivers before surgery had subjective visual problems while driving in daylight, and $69 \%$ while driving in darkness. After surgery these figures had been reduced to $6 \%$ and $24 \%$ (table 3 ).

A few months and 5 years after surgery, the frequency of subjective visual difficulties while driving in daylight was low. However, there was a significantly larger proportion of drivers with visual difficulties during night-time 5 years after surgery, although median VA was unchanged. The reason for this is unknown. Further investigation of this finding and the implications for crash incidence is clearly warranted.

The proportion of patients with a driving licence before surgery increased from $46 \%$ to 50\%, between 1992 and 19978 , although mean age was unchanged. Patients without a licence were mostly elderly women $(86 \%)$, who by tradition have never learnt to drive. In the age group 67-79 years, 91\% of males and $58 \%$ of females in Sweden have a valid licence. In 1991 the proportion of people aged 80+ with driving licence was $29 \%$, and in 2002, $51 \% .{ }^{11}$ In the industrialised society the number of elderly people is increasing because of longer lifespan. This fact, together with the escalating proportion of elderly women having a driving licence, and the higher incidence of cataract in women, ${ }^{12}{ }^{13}$ might account for a substantial number of cataract patients with a driving licence in the future.

Five years after surgery, $63 \%$ of the eligible patients with a driving licence were active drivers. In this group nine patients $(5 \%)$, did not fulfil the VA requirements. Starting in 1999, there is in Sweden an obligation for lorry and bus drivers older than 45 years of age to have a medical check up including VA to maintain a licence for these vehicles. This check up must be repeated every 10 years. At present there is no obligation for non-commercial car drivers to have their acuities checked, although this matter has been discussed.

In conclusion, before surgery subjective visual problems while driving were found in a large proportion of cataract patients and a substantial number of patients drove without fulfilling the visual requirements. Drivers with significant cataract, visual functional difficulties, and/or reduced VA

Table 3 Visual function of drivers before and after surgery and 5 years after surgery

\begin{tabular}{|c|c|c|c|}
\hline & Before surgery & After surgery & 5 years after \\
\hline No of actual drivers & 224 & 285 & 189 \\
\hline Mean age (years) (SD) & $68.3(11.3)$ & $68.9(11.9)$ & $70.3(11)$ \\
\hline Age range (years) & $36-89$ & $36-88$ & $35-91$ \\
\hline Males & $66 \%$ & $64 \%$ & $62 \%$ \\
\hline One eye operated for cataract & $25 \%(56 / 224)$ & $70 \%(199 / 285)$ & $33 \%(62 / 189)$ \\
\hline Both eyes had cataract surgery & - & $30 \%(86 / 285)$ & $67 \%(127 / 189)$ \\
\hline $\begin{array}{l}\text { Presenting visual acuity less than } 20 / 40 \\
\text { of the better eye }\end{array}$ & $16 \%(36 / 224)$ & $1 \%(2 / 285)$ & $5 \%(9 / 174)^{*}$ \\
\hline $\begin{array}{l}\text { Best corrected VA less than } 20 / 40 \\
\text { of the better eye }\end{array}$ & $11 \%(24 / 224)$ & $1 \%(2 / 285)$ & $3 \%(5 / 174)^{*}$ \\
\hline $\begin{array}{l}\text { Median log MAR (Snellen) PVA and } \\
\text { BCVA of the better seeing eye }\end{array}$ & $0.097(20 / 25)$ & $0(20 / 20)$ & $0(20 / 20)$ \\
\hline Visual difficulties, daytime driving $\dagger$ & $50 \%(110 / 222)$ & $6 \%(17 / 281)$ & $5 \%(9 / 188)$ \\
\hline Visual difficulties, night-time driving & $69 \%(150 / 217)$ & $24 \%(67 / 281)$ & $32 \%(61 / 188)$ \\
\hline Do not drive in darkness & $10 \%(21 / 217)$ & $10 \%(28 / 281)$ & $12 \%(22 / 188)$ \\
\hline
\end{tabular}

*VA data are based on 174 drivers as 15 of 189 participated with questionnaire only.

†A few answers are missing in each group, therefore the sums in the denominators do not equal the total number 
Table 4 Reasons stated for not driving

\begin{tabular}{|c|c|c|c|c|}
\hline & \multirow{2}{*}{$\begin{array}{l}\text { No of patients } \\
\text { (with VA data) }\end{array}$} & \multirow{2}{*}{$\frac{\text { Males }}{\text { No (\%) }}$} & \multirow{2}{*}{$\begin{array}{l}\text { Do not fulfil } \\
\text { the legal VA } \\
\text { requirements } \\
\text { No (\%) }\end{array}$} & \multirow{2}{*}{$\begin{array}{l}V A \geqslant 20 / 25 \text { in } \\
\text { the best eye } \\
\text { No (\%) }\end{array}$} \\
\hline & & & & \\
\hline Thinks vision too bad & $41(40)$ & $17 / 41(41)$ & $26 / 40(65)$ & $7 / 40$ (18) \\
\hline Good vision but insufficient health & $26(20)$ & $14 / 26(54)$ & $1 / 20(5)$ & $9 / 20(45)$ \\
\hline Uninterested, no need for a car & $38(36)$ & $6 / 38(16)$ & $0 / 36$ & $26 / 36(72)$ \\
\hline Healthy eyes and body but feels too old & $17(14)$ & $4 / 17(24)$ & $1 / 14(7)$ & $7 / 14(50)$ \\
\hline No licence because of traffic violation & $2(2)$ & $2 / 2(100)$ & $0 / 2$ & $2 / 2(100)$ \\
\hline No answer & $8(4)$ & $1 / 8(12)$ & $1 / 4(25)$ & $3 / 4(75)$ \\
\hline Total & $132(116)$ & $44 / 132$ (33) & $29 / 116(25)$ & $54 / 116(47)$ \\
\hline
\end{tabular}

should be prioritised for cataract surgery. ${ }^{14}{ }^{15}$ Five years after surgery only a few patients drove not fulfilling the requirements, but there were a larger proportion of patients with problems driving in darkness compared with a few months after surgery. The long term impact of cataract surgery in car drivers is beneficial.

\section{ACKNOWLEDGEMENTS}

The authors thank Ulla Lundmark at the Swedish National Register of Driving Licenses for providing data concerning driving licences. The study followed the tenets of the Declaration of Helsinki and was approved by the ethics committee of Umeå University.

Grants from Crown Princess Margareta's Committee for the Blind, Sweden and from the Umeå University Research Fund, are greatly acknowledged.

Presented in part at the annual meeting of the Association for Research in Vision and Ophthalmology (ARVO), Fort Lauderdale, FL, USA, May 1999. The authors' have no financial interest or are paid consultants to any commercial company.

\section{Authors' affiliations}

E Mönestam, B Lundquist, L Wachtmeister, Department of Clinical Sciences/Ophthalmology, Umeå University, Umeå, Sweden

\section{REFERENCES}

1 Owsley C, Stalvey B, Wells J, et al. Older drivers and cataract: driving habits and crash risk. J Geront Med Sci 1999;54A:M203-11.
2 Mönestam E, Wachtmeister L. Impact of cataract surgery on car driving: a population based study in Sweden. Br J Ophthalmol 1997;81:16-22.

3 Kahn HA, Leibowitz HM, Ganley JP, et al. The Framingham Eye Study. I. Outline and major prevalence findings. Am J Epidemiol 1977;106:571-3.

4 Mönestam E, Wachtmeister L. Dissatisfaction with cataract surgery in relation to visual results in a population-based study in Sweden. J Cataract Refract Surg 1999;25:1127-34

5 Steinberg EP, Tielsch JM, Schein OD, et al. The VF-14. An index of functional impairment in patients with cataract. Arch Ophthalmol 1994;1 12:630-8.

6 Cassard SD, Patrick DL, Damiano AM, et al. Reproducibility and responsiveness of the VF-14; an index of functional impairment in patients with cataracts. Arch Ophthalmol 1995;113:1508-13.

7 Alonso J, Espallargues M, Andersen T, et al. International applicability of the VF-14. An index of visual function in patients with cataracts. Ophthalmology 1997; 104:799-807.

8 Commission of the European Communities. Second Directive on Driving 1991;439:EC.

9 Lundström M, Stenevi U, Thorburn W. The Swedish National Cataract Register: a 9-year review. Acta Ophthal Scand 2002;80:248-57.

10 Mönestam E, Wachtmeister $L$. Change of subjective visual function in first-eye cataract patients when the rate of surgery increases in a population. Medical Care 2002;40:1080-9.

11 National Central Bureau of Statistics. Year book 2002; motorism in Sweden (SCB årsbok Bilismen i Sverige, 2002. www.bilsweden.se).

12 Klein BEK, Klein R, Ritter R. Is there evidence of an estrogen effect on agerelated lens opacities? Arch Ophthalmol 1994;112:85-91.

13 Mönestam E, Wactmeister L. Cataract surgery from a gender perspective-a population based study in Sweden. Acta Ophthalmol Scand 1998;76:711-16

14 Owsley C, Ball K, Sloane ME, et al. Visual/cognitive correlates of vehicle accidents in older drivers. Psychol Aging 1991;6:403-15.

15 Shinar D, Schieber F. Visual requirements for safety and mobility of older drivers. Hum factors 1991;33:507-19. 